\title{
Seletividade e Eficácia de Controle de Plantas Daninhas pela Associação entre Óleo Fúsel e Herbicidas em Cana-de-Açúcar ${ }^{1}$
}

\author{
Selectivity and Weed Control Efficacy of Fusel Oil and Herbicide Association in Sugarcane
}

\author{
PIZZO, I.V. ${ }^{2}$, AZANIA, C.A.M. ${ }^{3}$, AZANIA, A.A.P.M. ${ }^{4}$ e SCHIAVETTO, A.R. ${ }^{5}$
}

\begin{abstract}
RESUMO - Este trabalho objetivou estudar a seletividade da associação de óleo fúsel e herbicidas sobre cana-de-açúcar, cultivar IAC93-3046, e a eficácia de controle sobre as espécies Panicum maximum, Amaranthus deflexus, Ipomoea quamoclit, Brachiaria decumbens e Euphorbia heterophylla. O experimento foi instalado no Centro de Cana do Instituto Agronômico, localizado em Ribeirão Preto-SP, em delineamento de blocos casualizados, com 10 tratamentos e quatro repetições. As parcelas foram constituídas de seis linhas de cana-de-açúcar com $4 \mathrm{~m}$ de comprimento, espaçadas de $1,50 \mathrm{~m}\left(36 \mathrm{~m}^{2}\right)$, sendo metade semeada com plantas daninhas, para avaliação de controle, e a outra metade mantida no limpo, para avaliação da seletividade. Os tratamentos foram constituídos por herbicidas e sua associação com o óleo fúsel, sendo diuron+hexazinone $\left(1.170+330 \mathrm{~g} \mathrm{ha}^{-1}\right)$; diuron+hexazinone $\left(1.170+330 \mathrm{~g} \mathrm{ha}^{-1}\right)+$ óleo fúsel (25,0 L ha-1); diuron+hexazinone (819+231 $\left.\mathrm{g} \mathrm{ha}^{-1}\right)+$ óleo fúsel (25,0 L ha-1); metribuzin (1.920 $\left.\mathrm{g} \mathrm{ha}^{-1}\right)$; metribuzin $\left(1.920 \mathrm{~g} \mathrm{ha}^{-1}\right)+$ óleo fúsel $\left(25,0 \mathrm{~L} \mathrm{ha}^{-1}\right)$; metribuzin $\left(1.344 \mathrm{~g} \mathrm{ha}^{-1}\right)+$ óleo fúsel (25,0 L ha-1); amicarbazone (1.400 $\left.\mathrm{g} \mathrm{ha}^{-1}\right)$; amicarbazone (1.400 $\left.\mathrm{g} \mathrm{ha}^{-1}\right)$ + óleo fúsel (25,0 L ha-1); amicarbazone (980 $\left.\mathrm{g} \mathrm{ha}^{-1}\right)$ óleo fúsel $\left(25,0 \mathrm{~L} \mathrm{ha}^{-1}\right)$ e ausência de herbicidas. A aplicação dos tratamentos foi realizada com equipamento costal pressurizado e volume de calda correspondente a $250 \mathrm{~L} \mathrm{ha}^{-1}$, em pós-emergência da cultura $(30 \mathrm{~cm})$ e plantas daninhas (até $20 \mathrm{~cm}$ ). Os herbicidas diuron+hexazinone, metribuzin e amicarbazone isolados foram eficazes no controle de todas as espécies, mas, em dose completa e $70 \%$ da dose associados com óleo fúsel, não apresentaram controle satisfatório apenas às espécies I. quamoclit e E. heterophylla. Esses mesmos tratamentos foram seletivos ao cultivar IACSP 93-3046, ao comparar com a testemunha as variáveis altura, estande, diâmetro e produção de colmos, assim como aos atributos qualitativos. Entretanto, diuronthexazinone e amicarbazone em dose completa associados com óleo fúsel não foram seletivos à concentração de sólidos solúveis no caldo e na produção de colmos, respectivamente.
\end{abstract}

Palavras-chave: Saccharum spp., subproduto.

\begin{abstract}
This work aimed to study the selectivity of fusel oil and herbicide association in the sugarcane cultivar IAC93-3046, and the efficacy of controlling the species Panicum maximum, Amaranthus deflexus, Ipomoea quamoclit, Brachiaria decumbens and Euphorbia heterophylla. The experiment was set up at the Instituto Agronômico/Centro de Cana in Ribeirão Preto, Brazil, in a randomized block design with 10 treatments and 4 replicates. The plots were composed of six $4 \mathrm{~m}$ sugarcane lines, $1.50 \mathrm{~m}\left(36 \mathrm{~m}^{2}\right)$ spaced, with half being sown with weeds for control evaluation, and the other half without weeds for selectivity evaluation. The treatments were diuron thexazinone $\left(1,170+330 \mathrm{~g} \mathrm{ha}^{1}\right)$; diuron thexazinone $\left(1,170+330 \mathrm{~g} \mathrm{ha}^{-1}\right)+$ fusel oil (25.O L ha-1); diuronthexazinone $\left(819+231 \mathrm{~g} \mathrm{ha}^{-1}\right)+$ fusel oil (25.0 L ha-1); metribuzin (1,920 $\left.\mathrm{g} \mathrm{ha-1}\right)$; metribuzin (1,920 $\left.\mathrm{g} \mathrm{ha}^{-1}\right)+$ fusel oil (25.0 L ha $\left.\mathrm{L}^{-1}\right)$; metribuzin (1,344 $\left.\mathrm{g} \mathrm{ha}^{-1}\right)+$ fusel oil (25.0 L ha-1); amicarbazone $\left(1,400 \mathrm{~g} \mathrm{ha}^{-1}\right)$; amicarbazone $\left(1,400 \mathrm{~g} \mathrm{ha}^{-1}\right)+$ fusel oil $\left(25.0 \mathrm{~L} \mathrm{ha}^{-1}\right)$ and amicarbazone $\left(980 \mathrm{~g} \mathrm{ha}^{-1}\right)+$ fusel oil (25. O L hat $\mathrm{L}^{-1}$ and no herbicides. The application was performed with pressurized sprayer
\end{abstract}

1 Recebido para publicação em 6.5.2009 e na forma revisada em 15.6.2010.

2 Graduando em Eng. Agronômica, Estagiário de Iniciação Científica, Instituto Agronômico de Campinas (CNPq/Pibic/ IAC), <igorpizzo@itelefonica.com.br>; ${ }^{3}$ Engo$^{-}-A_{g r}{ }^{\circ}$., Pesquisador Científico, Dr., Instituto Agronômico de Campinas, <azania@iac.sp.gov.br>; ${ }^{4}$ Bióloga, Pesquisador Científico Voluntária, Dra., Instituto Agronômico de Campinas, <andrea.azania@hotmail.com>; ${ }^{5}$ Eng-a-Agr ${ }^{\mathrm{a}}$., Mestranda em Genética e Melhoramento de Plantas, Estagiária, Instituto Agronômico de Campinas, <anaschiavetto@bol.com.br>;

Planta Daninha, Viçosa-MG, v. 28, n. 2, p. 347-357, 2010 
and $250 \mathrm{~L} \mathrm{ha-1}$ volume underpost-emergence of the culture $(30 \mathrm{~cm})$ and weeds $(10-2 \mathrm{~cm})$. The herbicides diuron thexazinone, metribuzin and amicarbazone were effective in controlling all the species alone, but only I. quamoclit and $\boldsymbol{E}$. heterophylla did not present a satisfactory control at full dose and $70 \%$ of the dose combined with fusel oil. The same treatments were also selective for sugarcane cultivar IACSP 93-3046, when the variables height, stand, diameter and stalk yield, as well as the qualitative attributes were compared to the control. However, diuron thexazinone and amicarbazone at a full dose associated with fusel oil were not selective for Brix\% juice and stalk yield, respectively.

Keywords: Saccharum spp., by-product.

\section{INTRODUÇÃO}

O óleo fúsel é um resíduo gerado pelas usinas na destilação do álcool, utilizado como matéria-prima em outros processos industriais. O subproduto é um líquido levemente amarelo de odor desagradável, que também está presente nas bebidas alcoólicas e é responsável pelo sabor característico das aguardentes, determinando-lhes o seu buquê e aroma particular (Lima, 1964). Segundo Pérez et al. (2001), os constituintes do óleo fúsel são álcoois superiores da série de graxas, principalmente o álcool isoamilico.

A geração do subproduto nas usinas ocorre na coluna de retificação, no processo de obtenção do álcool. Esse subproduto também possui escassas informações quanto ao seu uso na agricultura, sendo vendido para indústrias de cosméticos e outras indústrias químicas. Segundo o Agrianual (2008), na safra 2007/ 2008, a produção total de álcool proveniente de cana-de-açúcar foi de aproximadamente 21,3 bilhões de litros. Isso significa que foram produzidos, aproximadamente, 53,2 milhões de litros de óleo fúsel, sem aplicação direta nas unidades produtoras.

$\mathrm{Na}$ agricultura, observou-se inviabilização completa das sementes de Brachiaria decumbens submetidas a diferentes concentrações $(100,50,25$ e 12,5\% v/v), além da redução da viabilidade das sementes de Sida rhombifolia nas maiores concentrações de aplicação de óleo fúsel (Azania et al., 2003). Em outro trabalho, constatou-se também potencial dessecante sobre essas espécies (Azania et al., 2004), porém em doses muito elevadas, superiores a $50 \mathrm{~m}^{3} \mathrm{ha}^{-1}$.

Em continuidade aos estudos e na tentativa de diminuir as elevadas doses utilizadas em outros trabalhos, o óleo fúsel associado com glifosato dessecou o perfilho principal de plantas de cana-de-açúcar e controlou diferentes plantas daninhas em uma comunidade infestante natural, com exceção de espécies dos gêneros Commelina e Cyperus (Azania et al., 2008).

No campo, é comum os produtores associarem diferentes herbicidas diretamente no tanque de pulverização, embora essa seja uma prática proibida, segundo Rodrigues \& Almeida (2005), pelo Ministério da Agricultura, Pecuária e Abastecimento (Brasil, 2008), por meio da Instrução Normativa no 46 de 2002. Nesse sentido, é comum e permitida por lei a comercialização de formulações prontas de duas ou mais moléculas, a exemplo de herbicidas tradicionais, como diuron thexazinone, etc.

Entretanto, para finalidades técnicas, são importantes pesquisas que objetivem a eficácia de controle e seletividade de dois ou mais herbicidas associados em uma única aplicação, para posterior possibilidade de registro de novas formulações prontas. Considerando a necessidade técnica de verificar a seletividade e a eficácia das associações realizadas diretamente no tanque, o potencial herbicida e o baixo valor comercial do óleo fúsel, este trabalho objetivou estudar a seletividade da associação óleo fúsel e herbicidas para o cultivar IACSP 93-3046 e a eficácia de controle sobre diferentes plantas daninhas.

\section{MATERIAL E MÉTODOS}

O experimento foi instalado no Centro de Cana do Instituto Agronômico de Campinas, localizado em Ribeirão Preto-SP, em Latossolo Vermelho, textura muito argilosa $(61,2 \%$ de argila, $16,63 \%$ de areia e $22,17 \%$ de silte). 
A área experimental era constituída pela cultura da cana-de-açúcar, cultivar IACSP 93-3046, soqueira do segundo corte. O delineamento utilizado foi em blocos casualizados, com 10 tratamentos e quatro repetições. As parcelas foram constituídas de seis linhas de cana-de-açúcar, com $4 \mathrm{~m}$ de comprimento e espaçadas de $1,50 \mathrm{~m}\left(36 \mathrm{~m}^{2}\right)$, sendo metade semeada com plantas daninhas para avaliação de controle e a outra mantida no limpo para avaliação da seletividade. Assim, no local de avaliação de controle de plantas daninhas, o delineamento ficou em blocos casualizados em esquema de parcelas subdivididas, sendo os herbicidas aplicados nas parcelas e as espécies de plantas daninhas semeadas isoladamente nas subparcelas (entrelinhas). No local de avaliação da seletividade, o delineamento estatístico ficou em blocos casualizados, com quatro repetições em cada tratamento.

Foram utilizadas sementes das espécies Ipomoea quamoclit, Amaranthus deflexus, Panicum maximum, Euphorbia heterophylla e Brachiaria decumbens para composição da flora infestante, sendo a escolha das espécies atribuída àquelas mais frequentes nos canaviais. A semeadura nas entrelinhas das parcelas (subparcelas) foi realizada no dia 9/11/2007, com quantidade de sementes suficiente para proporcionar a emergência de 100 plantas, de acordo com o teste de germinação fornecido pela empresa produtora.

Os tratamentos foram constituídos pela aplicação de herbicidas isolados ou em associação com o óleo fúsel: diuronthexazinone $\left(1.170+330 \mathrm{~g} \mathrm{ha}^{-1}\right)$; diuronthexazinone $\left(1.170+330 \mathrm{~g} \mathrm{ha}^{-1}\right)+$ óleo fúsel $\left(25,0 \mathrm{~L} \mathrm{ha}^{-1}\right)$; diuron thexazinone $\left(819+231 \mathrm{~g} \mathrm{ha}^{-1}\right)+$ óleo fúsel (25,0 $\left.\mathrm{L} \mathrm{ha}^{-1}\right)$; metribuzin (1.920 $\mathrm{g} \mathrm{ha}^{-1}$ ); metribuzin $\left(1.920 \mathrm{~g} \mathrm{ha}^{-1}\right)+$ óleo fúsel (25,0 L ha-1); metribuzin (1.344 $\left.\mathrm{g} \mathrm{ha}^{-1}\right)+$ óleo fúsel (25,0 $\left.\mathrm{L} \mathrm{ha}^{-1}\right)$; amicarbazone (1.400 $\left.\mathrm{g} \mathrm{ha}^{-1}\right)$; amicarbazone $\left(1.400 \mathrm{~g} \mathrm{ha}^{-1}\right)+$ óleo fúsel (25,0 L ha-1); amicarbazone (980 $\left.\mathrm{g} \mathrm{ha}^{-1}\right)+$ óleo fúsel (25,0 L ha-1); e ausência de herbicidas.

Na escolha dos herbicidas, optou-se pelo amicarbazone, por ser de uso mais recente em cana-de-açúcar, e pela mistura formulada de diuronthexazinone e metribuzin, por serem de uso tradicional em cana-de-açúcar, com vários resultados em literatura atestando a eficácia e a seletividade (Clement et al., 1979; Maciel et al., 2008).

Nos tratamentos herbicidas com ausência de óleo fúsel, a dose utilizada foi a recomendada pelo fabricante (Rodrigues \& Almeida, 2005). Nos tratamentos em associação com óleo fúsel, os herbicidas foram aplicados em 100 e $70 \%$ da quantidade recomendada, enquanto o óleo fúsel foi ministrado em quantidade de $25 \mathrm{~L} \mathrm{ha}^{-1}$. A diminuição na dose dos herbicidas foi uma tentativa de minimizar problemas com fitotoxicidade, a exemplo de reduções entre 20 e $30 \%$ observadas na prática, enquanto a dose do óleo fúsel foi obtida observando-se os poucos trabalhos existentes com o subproduto (Azania et al., 2003, 2004, 2008).

Para aplicação, foi utilizado equipamento costal pressurizado $\left(\mathrm{CO}_{2}\right)$ munido de barra com quatro pontas turbo Teejet (TT 11002), espaçadas de $50 \mathrm{~cm}$ entre si, com pressão de $151,3 \mathrm{~N} \mathrm{~m}^{-2}$ (34 psi) e volume de calda correspondente a $250 \mathrm{~L} \mathrm{ha}^{-1}$. A aplicação foi realizada no dia 16/12/2007 em pós-emergência das plantas de cana-de-açúcar (120 dias após a última colheita) e plantas daninhas, com umidade relativa média de $46,6 \%$, temperatura média de $33,7{ }^{\circ} \mathrm{C}$ e rajadas de vento entre 0,8 e $3,0 \mathrm{~km} \mathrm{~h}^{-1}$.

No momento da aplicação, as plantas de cana-de-açúcar apresentavam altura média de $30 \mathrm{~cm}$ e as plantas daninhas tinham portes diferentes, devido ao comportamento biológico de cada espécie. As espécies $B$. decumbens e $P$. maximum apresentaram atraso na germinação, com consequente interferência no porte das demais espécies. Assim, no momento da aplicação, $B$. decumbens e $P$. maximum apresentaram altura não superior a $10 \mathrm{~cm}$, e as demais, não superior a $20 \mathrm{~cm}$.

Para o estudo da eficácia de controle, foi realizada avaliação das plantas daninhas aos 15, 30, 60 e 90 dias após tratamento (DAT), avaliando-se o percentual de controle. Foram atribuídas notas visuais de controle de acordo com uma escala variando de 0 a $100 \%$, em que 0 corresponde à ausência de controle de plantas daninhas e 100 ao total controle destas; a densidade de plantas daninhas aos 90 DAT também foi estudada, 
amostrando-se $0,25 \mathrm{~m}^{2}$, lançado aleatoriamente, em cada subparcela, a partir de um quadrado metálico de dimensões de $0,50 \times 0,50 \mathrm{~m}$. As plantas amostradas foram cortadas rente ao solo, acondicionadas em sacos de papel e secas em estufa de circulação forçada de ar à temperatura de $70^{\circ} \mathrm{C}$, até peso constante.

Para o estudo de seletividade, foram observados os sintomas de intoxicação nas plantas de cana-de-açúcar aos 15 e 30 DAT. As avaliações constaram de notas percentuais e visuais variando de 0 a $100 \%$, sendo $0 \%$ correspondente à ausência de injúrias e 100\% à morte de todas as plantas.

Neste estudo, também foram aferidos a altura das plantas aos 30, 60 e 90 DAT, medindo-se a distância do solo até a primeira folha completamente desenvolvida, em 10 plantas de cana-de-açúcar de duas linhas centrais de cada parcela; o estande aos 30, 60 e 90 DAT, contando-se todos os perfilhos das plantas de cana-de-açúcar das três linhas centrais; o diâmetro de colmos aos 90 DAT (210 dias após a última colheita), aferindo-se o diâmetro de 10 colmos de cana-de-açúcar de duas linhas centrais de cada parcela; e o peso dos colmos aos 90 DAT, coletando-se três feixes com 10 colmos de cana-de-açúcar cada, nas três linhas centrais de cada parcela. Os colmos foram cortados em sequência e tiveram o peso determinado por balança eletrônica.

Na sequência, considerando o estande, o peso obtido dos colmos e a área útil da amostragem, aferidos aos 90 DAT, estimou-se a produtividade em toneladas de cana-de-açúcar por hectare, utilizando-se da metodologia de Landell (1995). Após a pesagem das amostras, o feixe coletado na linha central foi enviado ao laboratório de sacarose para determinação do Brix e Pol\%caldo, além dos cálculos de Pureza\%caldo, Açúcares Redutores\%caldo, Fibra\%cana e da quantidade de açúcar total recuperável (ATR) do caldo, conforme metodologia adaptada pela CONSECANA (2006).

A análise estatística dos resultados foi realizada por meio da análise de variância (teste F). A comparação de médias de tratamentos foi feita empregando-se o teste de Tukey a $5 \%$ de probabilidade.

\section{RESULTADOS E DISCUSSÃO}

No decorrer do ensaio, as condições climáticas foram atípicas, pois as chuvas se intensificaram somente no final do mês de outubro e, ainda, foram inferiores à média histórica (Tabela 1). Essa condição propiciou atraso no desenvolvimento inicial das plantas de cana-de-açúcar, o que pode explicar a altura de $30 \mathrm{~cm}$ das plantas da cultura na ocasião da aplicação dos herbicidas, que se deu quatro meses após a colheita.

Nas parcelas testemunhas foram obtidos, visualmente, os percentuais de cobertura de cada espécie estudada (Tabela 2). Verificou-se que Panicum maximum e Brachiaria decumbens apresentaram desenvolvimento inicial relativamente lento, o qual se acentou após os 60 DAT. Amaranthus deflexus desenvolveu-se de forma mais uniforme ao longo do ensaio, com pequeno acréscimo aos 90 DAT, ao passo que Ipomoea quamoclit e Euphorbia heterophylla mostraram desenvolvimento inicial vigoroso, demonstrando grande capacidade competitiva, principalmente para I. quamoclit.

\section{Controle de plantas daninhas}

Observando os percentuais de controle proporcionados pelos tratamentos aos 15 e 30 DAT (Tabela 3) sobre a comunidade infestante semeada, verificou-se que a maior parte apresentou controles superiores a $85 \%$, tidos como suficientes na prática, excetuando-se metribuzin $\left(1.344 \mathrm{~g} \mathrm{ha}^{-1}\right)+$ óleo fúsel $(\mathrm{OF})$

Tabela 1 - Precipitações e temperaturas médias ocorridas durante o período de condução do experimento. Ribeirão Preto-SP, 2008

\begin{tabular}{|l|c|c|c|c|}
\hline \multirow{2}{*}{ Mês } & \multicolumn{2}{|c|}{ Precipitação $(\mathrm{mm})$} & \multicolumn{2}{c|}{ Temperatura média $\left({ }^{\circ} \mathrm{C}\right)$} \\
\cline { 2 - 5 } & $\begin{array}{c}\text { Valor } \\
\text { observado }\end{array}$ & $\begin{array}{c}\text { Média dos } \\
\text { últimos } \\
17 \text { anos }\end{array}$ & $\begin{array}{c}\text { Valor } \\
\text { observado }\end{array}$ & $\begin{array}{c}\text { Média dos } \\
\text { últimos } \\
17 \text { anos }\end{array}$ \\
\hline Agosto & 0,0 & 14,4 & 21,9 & 21,6 \\
\hline Setembro & 3,0 & 60,6 & 24,9 & 23,2 \\
\hline Outubro & 49,4 & 108,5 & 26,1 & 24,6 \\
\hline Novembro & 125,4 & 182,6 & 23,9 & 24,3 \\
\hline Dezembro & 179,6 & 247,3 & 25,2 & 24,6 \\
\hline Janeiro & 364,6 & 298,5 & 24,0 & 24,7 \\
\hline Fevereiro & 197,2 & 236,7 & 24,5 & 24,8 \\
\hline Março & 201,9 & 159,3 & 23,7 & 24,6 \\
\hline
\end{tabular}

Fonte: CIIAGRO (2008) 
Seletividade e eficácia de controle de plantas daninhas ...

Tabela 2 - Dados médios de cobertura (\%) sobre o solo, densidade e massa seca das espécies estudadas na área testemunha

\begin{tabular}{|c|c|c|c|c|c|c|c|}
\hline \multirow{2}{*}{ Espécie } & \multicolumn{5}{|c|}{ Cobertura $(\%)$} & \multirow{2}{*}{$\frac{\mathrm{DS}}{90 \mathrm{DAT}^{2 /}}$} & \multirow{2}{*}{$\frac{\mathrm{MS}(\mathrm{g})}{90 \mathrm{DAT}^{2}}$} \\
\hline & Inicial $^{1 / 1}$ & $15 \mathrm{DAT}^{2 /}$ & $30 \mathrm{DAT}^{2} /$ & $60 \mathrm{DAT}^{2} \stackrel{2}{ }$ & $90 \mathrm{DAT}^{2 /}$ & & \\
\hline P. maximum & 13,88 & 12,50 & 10,00 & 27,50 & 40,00 & 10,00 & 9,27 \\
\hline A. deflexus & 17,38 & 10,00 & 15,00 & 10,00 & 21,25 & 6,00 & 1,17 \\
\hline I. quamoclit & 91,25 & 83,75 & 75,00 & 75,00 & 75,00 & 133,00 & 196,88 \\
\hline B. decumbens & 19,00 & 22,50 & 11,25 & 32,50 & 50,00 & 9,00 & 12,10 \\
\hline E. heterophylla & 66,63 & 70,00 & 75,00 & 67,50 & 13,75 & 16,00 & 6,10 \\
\hline
\end{tabular}

${ }_{1}^{1}$ Dados médios referentes a 40 subparcelas $\left(2,0 \mathrm{~m}^{-2}\right)$ de uma mesma espécie; $\stackrel{2}{ }$ dados médios referentes a quatro subparcelas $\left(2,0 \mathrm{~m}^{-2}\right)$ de uma mesma espécie no tratamento testemunha; DS - densidade (plantas $\mathrm{m}^{2}$ ); MS - massa seca $(\mathrm{g})$.

Tabela 3 - Porcentagem de controle para os diferentes tratamentos herbicidas e espécies daninhas estudadas nas diferentes épocas após aplicação. Ribeirão Preto, 2008

\begin{tabular}{|c|c|c|c|c|}
\hline \multirow{3}{*}{ Variável } & \multicolumn{4}{|c|}{ Época de avaliação (DAT) } \\
\hline & 15 & 30 & 60 & 90 \\
\hline & orig. $(\%)$ & orig. $(\%)$ & orig.(\%) & orig. $(\%)$ \\
\hline \multicolumn{5}{|l|}{ Herbicida (A) } \\
\hline diuron+hexazinone $\left(1.170 / 0,330 \mathrm{~g} \mathrm{ha}^{-1}\right)$ & $96,50 \mathrm{~A}$ & $96,50 \mathrm{~A}$ & $93,50 \mathrm{~A}$ & $87,5 \mathrm{AB}$ \\
\hline diuron+hexazinone $\left(1.170 / 0,330 \mathrm{~g} \mathrm{ha}^{-1}\right)+\mathrm{OF}\left(25 \mathrm{~L} \mathrm{ha}^{-1}\right)$ & $91,25 \mathrm{~A}$ & $89,00 \mathrm{~A}$ & $85,00 \mathrm{~A}$ & $89,25 \mathrm{AB}$ \\
\hline diuron+hexazinone $\left(0,819 / 0,231 \mathrm{~g} \mathrm{ha}^{-1}\right)+$ OF $\left(25 \mathrm{~L} \mathrm{ha}^{-1}\right)$ & $87,50 \mathrm{~A}$ & $86,5 \mathrm{~A}$ & $82,25 \mathrm{AB}$ & $86,25 \mathrm{AB}$ \\
\hline metribuzin $\left(1.920 \mathrm{~g} \mathrm{ha}^{-1}\right)$ & $92,00 \mathrm{~A}$ & $93,5 \mathrm{~A}$ & $93,50 \mathrm{~A}$ & $93,25 \mathrm{~A}$ \\
\hline metribuzin $\left(1.920 \mathrm{~g} \mathrm{ha}^{-1}\right)+$ OF $\left(25 \mathrm{~L} \mathrm{ha}^{-1}\right)$ & $84,25 \mathrm{AB}$ & $82,5 \mathrm{AB}$ & $77,95 \mathrm{AB}$ & $83,25 \mathrm{AB}$ \\
\hline metribuzin $\left(1.344 \mathrm{~g} \mathrm{ha}^{-1}\right)+\mathrm{OF}\left(25 \mathrm{~L} \mathrm{ha}^{-1}\right)$ & $67,25 \mathrm{~B}$ & $64,5 \mathrm{~B}$ & $57,00 \mathrm{~B}$ & $65,50 \mathrm{~B}$ \\
\hline amicarbazone $\left(1.400 \mathrm{~g} \mathrm{ha}^{-1}\right)$ & $91,05 \mathrm{~A}$ & $89,2 \mathrm{~A}$ & $82,55 \mathrm{AB}$ & $83,10 \mathrm{AB}$ \\
\hline amicarbazone $\left(1.400 \mathrm{~g} \mathrm{ha}^{-1}\right)+\mathrm{OF}\left(25 \mathrm{~L} \mathrm{ha}^{-1}\right)$ & $94,00 \mathrm{~A}$ & $96,5 \mathrm{~A}$ & $91,50 \mathrm{~A}$ & $89,75 \mathrm{AB}$ \\
\hline amicarbazone $\left(0,980 \mathrm{~g} \mathrm{ha}^{-1}\right)+$ OF $\left(25 \mathrm{~L} \mathrm{ha}^{-1}\right)$ & $89,50 \mathrm{~A}$ & $87,5 \mathrm{~A}$ & $83,00 \mathrm{AB}$ & $83,5 \mathrm{AB}$ \\
\hline \multicolumn{5}{|l|}{ Espécie (B) } \\
\hline Panicum maximum & $95,00 \mathrm{AB}$ & $93,33 \mathrm{AB}$ & $86,36 \mathrm{~A}$ & $85,00 \mathrm{~A}$ \\
\hline Amaranthus deflexus & $96,94 \mathrm{~A}$ & $99,72 \mathrm{~A}$ & $99,44 \mathrm{~A}$ & $98,75 \mathrm{~A}$ \\
\hline Ipomoea quamoclit & $86,81 \mathrm{~B}$ & $83,33 \mathrm{~B}$ & $67,22 \mathrm{~B}$ & $62,92 \mathrm{~B}$ \\
\hline Brachiaria decumbens & $97,78 \mathrm{~A}$ & $97,64 \mathrm{~A}$ & $92,78 \mathrm{~A}$ & $88,61 \mathrm{~A}$ \\
\hline Euphorbia heterophylla & $64,19 \mathrm{~B}$ & $62,47 \mathrm{C}$ & $68,78 \mathrm{~B}$ & $87,69 \mathrm{~A}$ \\
\hline & \multicolumn{4}{|c|}{$\mathrm{F}$} \\
\hline Blocos & $0,81 \mathrm{NS}$ & $1,05 \mathrm{NS}$ & $0,91 \mathrm{NS}$ & $4,45^{*}$ \\
\hline Herbicidas (A) & $4,43^{* *}$ & $5,40^{* *}$ & $3,71 * *$ & $1,93^{*}$ \\
\hline Espécies (B) & $30,22 * *$ & $30,46^{* *}$ & $14,62 * *$ & $8,35 * *$ \\
\hline $\mathrm{A} \times \mathrm{B}$ & $1,62 *$ & $2,41 * *$ & $2,14 * *$ & $1,47 \mathrm{NS}$ \\
\hline CV $(\%)$ parcela & 20,71 & 21,46 & 31,28 & 30,18 \\
\hline CV $(\%)$ subparcela & 17,43 & 18,99 & 27,23 & 32,39 \\
\hline
\end{tabular}

Orig. - dados originais. DAT (dias após tratamento). OF - óleo fúsel. ${ }^{* *}$ significativo a $1 \%$ de probabilidade pelo teste $\mathrm{F} .{ }^{*}$ significativo a $5 \%$ de probabilidade pelo teste F. NS - não significativo. Letras iguais na mesma coluna não diferem entre si pelo teste de Tukey a $5 \%$.

(25 $\mathrm{L} \mathrm{ha}^{-1}$ ), que apresentou 67,25\% aos 15 DAT e $64,5 \%$ aos 30 DAT, considerados insuficientes.

Nesse período de avaliação, constatou-se que os tratamentos envolvendo metribuzin com acréscimo de óleo fúsel não apresentaram eficácia de controle adequada sobre as espécies estudadas. Assim, quando se observam ambos os tratamentos, não se constatam diferenças estatísticas (Tabela 3).

Aos 60 e 90 DAT, observou-se a menor eficácia da associação de metribuzin e óleo 
fúsel, em especial do tratamento metribuzin $\left(1.344 \mathrm{~g} \mathrm{ha}^{-1}\right)+$ OF $\left(25 \mathrm{~L} \mathrm{ha}^{-1}\right)$, devido ao menor percentual de controle. Entretanto, os demais tratamentos mostraram maior eficácia de controle sobre as espécies estudadas.

Ao considerar cada espécie estudada quanto ao controle, constatou-se que os tratamentos foram mais eficazes sobre Amaranthus deflexus, seguida de Brachiaria decumbens, Panicum maximum, Ipomoea quamoclit e Euphorbia heterophylla, que apresentaram, respectivamente, 98,7;94,2;89,9;75,0; e 65,8\% como média de controle no período de 15 a 90 DAT (Tabela 3).

As espécies I. quamoclit e E. heterophylla mostraram maior tolerância ao controle durante o período avaliado. I. quamoclit apresentou menor percentual de controle à medida que as avaliações se aproximavam dos 90 DAT, enquanto $E$. heterophylla foi mais bem controlada quando as avaliações já estavam chegando ao final (Tabela 3).

A espécie E. heterophylla possui porte herbáceo e pode ser prejudicada pelo sombreamento da cultura (Kissmann \& Groth, 1997). Assim, possivelmente não se pode associar o aumento na eficácia de controle sobre as plantas de $E$. heterophylla aos 90 DAT aos tratamentos utilizados, pois nessa ocasião as plantas estavam em final de ciclo e prejudicadas pelo sombreamento da cultura, refletindo nos maiores controles observados na Tabela 3.

As espécies de Ipomoea possuem elevada dormência em suas sementes (Azania et al., 2006), bem como hábito de crescimento trepador, conferindo às plantas a capacidade de envolver-se entre os colmos da cultura e expor suas folhas à luz solar, mantendo a atividade fotossintética das plantas. Essa biologia pode explicar os resultados de controle obtidos aos 90 DAT, pois no início os tratamentos foram eficazes, mas, com o passar do tempo, novos fluxos de emergência surgiram e as plantas se desenvolveram e expuseram as folhas sobre o ápice da cultura, refletindo nos menores controles observados na Tabela 3.

Os baixos valores obtidos para controle de I. quamoclit e E. heterophylla foram mais pronunciados nos tratamentos contendo metribuzin $\left(1.920 \mathrm{~g} \mathrm{ha}^{-1}\right)+$ OF $\left(25 \mathrm{~L} \mathrm{ha}^{-1}\right) \mathrm{e}$ metribuzin $\left(1.344 \mathrm{~g} \mathrm{ha}^{-1}\right)+$ OF $\left(25 \mathrm{~L} \mathrm{ha}^{-1}\right)$, conforme se observa na Tabela 4 .

Entretanto, aos 90 DAT não se observou mais interação entre os tratamentos sobre essas espécies invasoras (Tabela 3). Essa situação pode ser atribuída ao fato de os herbicidas terem sua concentração no solo reduzida à medida que o tempo se distancia do periodo da aplicação, aproximando-se do seu limite de persistência. A mistura pronta de diuronthexazinone e amicarbazone possui persistência superior a 100 dias no solo, e o metribuzin, de até 60 dias (Rodrigues \& Almeida, 2005). Assim, aos 90 dias após aplicação, a persistência das moléculas no solo estava reduzida, e esse fato pode ter influenciado na não interação dos herbicidas e espécies. Assim, optou-se por apresentar a densidade e massa seca das plantas daninhas (Figura 1), na tentativa de interpretar os resultados aos 90 DAT.

A espécie $P$. maximum apresentou controle similar ao se compararem os tratamentos diuronthexazinone isolado e em mistura com óleo fúsel (Tabela 4), comprovando a eficácia da redução da dose do herbicida quando associado ao óleo fúsel, bem como do herbicida isolado. Quanto aos tratamentos envolvendo metribuzin, verificou-se menor tendência de controle para essa espécie quando a dose do herbicida associado ao óleo fúsel foi reduzida, ao passo que o produto isolado foi eficaz. Já para os tratamentos envolvendo amicarbazone, observou-se acréscimo no controle quando o óleo fúsel foi associado à dose recomendada do herbicida amicarbazone $\left(1.400 \mathrm{~g} \mathrm{ha}^{-1}\right)+\mathrm{OF}$ (25 L ha ${ }^{-1}$ ), aos 60 DAT. Contudo, essas diferenças observadas na espécie $P$. maximum não foram detectadas estatisticamente.

A espécie Amaranthus deflexus (Tabela 4) foi satisfatoriamente controlada pelos tratamentos, apresentando apenas um atraso na eficácia de metribuzin $\left(1.344 \mathrm{~g} \mathrm{ha}^{-1}\right)+\mathrm{OF}$ (25 L ha-1) aos 15 DAT; entretanto, aos 30 DAT já não se observou mais nenhum prejuízo, embora não significativo pelo teste de médias. Assim, A. deflexus demonstrou não ser uma espécie de dificil controle pelos tratamentos empregados e que permite o uso de reduções de doses dos herbicidas estudados, quando associados ao óleo fúsel. 
Tabela 4 - Desdobramento da interação herbicidas x espécies para porcentagem de controle das plantas daninhas, Ribeirão Preto-SP, 2008

\begin{tabular}{|c|c|c|c|c|c|c|c|c|c|c|}
\hline & \multirow{3}{*}{ Espécie } & \multicolumn{9}{|c|}{ Tratamento } \\
\hline & & $\mathrm{T} 1$ & $\mathrm{~T} 2$ & T3 & $\mathrm{T} 4$ & T5 & T6 & $\mathrm{T} 7$ & $\mathrm{~T} 8$ & T9 \\
\hline & & orig.(\%) & orig. $(\%)$ & orig.(\%) & orig.(\%) & orig.(\%) & orig.(\%) & orig.(\%) & orig.(\%) & orig. $(\%)$ \\
\hline \multirow{5}{*}{$\begin{array}{c}15 \\
\text { (DAT) }\end{array}$} & P. maximum & $100,0 \mathrm{Aa}$ & $100,0 \mathrm{Aa}$ & $97,5 \mathrm{Aa}$ & $97,5 \mathrm{Aa}$ & $97,5 \mathrm{Aa}$ & $85,0 \mathrm{ABa}$ & $90,0 \mathrm{Aa}$ & $97,5 \mathrm{Aa}$ & $90,0 \mathrm{Aa}$ \\
\hline & A. deflexus & $100,0 \mathrm{Aa}$ & $100,0 \mathrm{Aa}$ & $100,0 \mathrm{Aa}$ & $100,0 \mathrm{Aa}$ & $100,0 \mathrm{Aa}$ & $75,0 \mathrm{ABa}$ & $100,0 \mathrm{Aa}$ & $97,5 \mathrm{Aa}$ & $100,0 \mathrm{Aa}$ \\
\hline & I. quamoclit & $95,0 \mathrm{Aa}$ & $85,0 \mathrm{Aa}$ & $82,5 \mathrm{Aa}$ & $100,0 \mathrm{Aa}$ & $80,0 \mathrm{Aa}$ & $66,3 \mathrm{Ba}$ & $90,0 \mathrm{Aa}$ & $97,5 \mathrm{Aa}$ & $85,0 \mathrm{Aa}$ \\
\hline & B. decumbens & $100,0 \mathrm{Aa}$ & $100,0 \mathrm{Aa}$ & $95,0 \mathrm{Aa}$ & $95,0 \mathrm{Aa}$ & $100,0 \mathrm{Aa}$ & $97,5 \mathrm{Aa}$ & $95,0 \mathrm{Aa}$ & $95,0 \mathrm{Aa}$ & $100,0 \mathrm{Aa}$ \\
\hline & E. heterophylla & $87,5 \mathrm{Aa}$ & 71,3 Aab & $62,5 \mathrm{Bab}$ & $65,0 \mathrm{Bab}$ & $43,8 \mathrm{Bbc}$ & $12,5 \mathrm{Cc}$ & $80,3 \mathrm{Aa}$ & $82,5 \mathrm{Aa}$ & $72,5 \mathrm{Aab}$ \\
\hline \multirow{5}{*}{$\begin{array}{c}30 \\
(\mathrm{DAT})\end{array}$} & P. maximum & $100,0 \mathrm{Aa}$ & $100,0 \mathrm{Aa}$ & $95,0 \mathrm{Aa}$ & $100,0 \mathrm{Aa}$ & $95,0 \mathrm{Aa}$ & $77,5 \mathrm{Aa}$ & $87,5 \mathrm{Aa}$ & $100,0 \mathrm{Aa}$ & $85,0 \mathrm{Aa}$ \\
\hline & A. deflexus & $100,0 \mathrm{Aa}$ & $100,0 \mathrm{Aa}$ & $100,0 \mathrm{Aa}$ & $100,0 \mathrm{Aa}$ & $100,0 \mathrm{Aa}$ & $97,5 \mathrm{Aa}$ & $100,0 \mathrm{Aa}$ & $100,0 \mathrm{Aa}$ & $100,0 \mathrm{Aa}$ \\
\hline & I. quamoclit & $95,0 \mathrm{Aa}$ & $87,5 \mathrm{Aa}$ & $85,0 \mathrm{ABa}$ & $100,0 \mathrm{Aa}$ & $87,5 \mathrm{Aa}$ & $32,5 \mathrm{Bb}$ & $85,0 \mathrm{Aa}$ & $95,0 \mathrm{Aa}$ & $82,5 \mathrm{Aa}$ \\
\hline & B. decumbens & $98,8 \mathrm{Aa}$ & $100,0 \mathrm{Aa}$ & $95,0 \mathrm{Aa}$ & $95,0 \mathrm{Aa}$ & $100,0 \mathrm{Aa}$ & $100,0 \mathrm{Aa}$ & $92,5 \mathrm{Aa}$ & $97,5 \mathrm{Aa}$ & $100,0 \mathrm{Aa}$ \\
\hline & E. heterophylla & $88,8 \mathrm{Aa}$ & $57,5 \mathrm{Bab}$ & $57,5 \mathrm{Bab}$ & $72,5 \mathrm{Aa}$ & $30,0 \mathrm{Bbc}$ & $15,0 \mathrm{Bc}$ & $81,0 \mathrm{Aa}$ & $90,0 \mathrm{Aa}$ & $70,0 \mathrm{Aa}$ \\
\hline \multirow{5}{*}{$\begin{array}{c}60 \\
(\mathrm{DAT})\end{array}$} & P. maximum & $97,5 \mathrm{Aa}$ & $100,0 \mathrm{Aa}$ & $95,0 \mathrm{Aa}$ & $97,5 \mathrm{Aa}$ & $99,8 \mathrm{Aa}$ & $60,0 \mathrm{Aba}$ & $65,0 \mathrm{Aa}$ & $92,5 \mathrm{Aa}$ & $70,0 \mathrm{Aa}$ \\
\hline & A. deflexus & $100,0 \mathrm{Aa}$ & $100,0 \mathrm{Aa}$ & $100,0 \mathrm{Aa}$ & $100,0 \mathrm{Aa}$ & $95,0 \mathrm{Aa}$ & $100,0 \mathrm{Aa}$ & $100,0 \mathrm{Aa}$ & $100,0 \mathrm{Aa}$ & $100,0 \mathrm{Aa}$ \\
\hline & I. quamoclit & $80,0 \mathrm{Aa}$ & $65,0 \mathrm{Aa}$ & $60,0 \mathrm{Aa}$ & $100,0 \mathrm{Aa}$ & $65,0 \mathrm{ABa}$ & $2,5 \mathrm{Cb}$ & $75,0 \mathrm{Aa}$ & $90,0 \mathrm{Aa}$ & $67,5 \mathrm{Aa}$ \\
\hline & B. decumbens & $97,5 \mathrm{Aa}$ & $100,0 \mathrm{Aa}$ & $87,5 \mathrm{Aa}$ & $87,5 \mathrm{Aa}$ & $95,0 \mathrm{Aa}$ & $100,0 \mathrm{Aa}$ & $82,5 \mathrm{Aa}$ & $85,0 \mathrm{Aa}$ & $100,0 \mathrm{Aa}$ \\
\hline & E. heterophylla & $92,5 \mathrm{Aa}$ & 60,0 Aabc & $68,8 \mathrm{Aabc}$ & $82,5 \mathrm{Aab}$ & $35,0 \mathrm{Bbc}$ & $22,5 \mathrm{BCc}$ & $90,3 \mathrm{Aa}$ & $90,0 \mathrm{Aa}$ & 77,5 Aab \\
\hline
\end{tabular}

DAT - dias após tratamento; T1-diuron+hexazinone $\left(1.170+330 \mathrm{~g} \mathrm{ha}^{-1}\right)$; T2-diuron+hexazinone $\left(1.170+330 \mathrm{~g} \mathrm{ha}^{-1}\right)+\mathrm{OF}\left(25 \mathrm{~L} \mathrm{ha}^{-1}\right)$; T3-diuron+hexazinone $\left(819+231 \mathrm{~g} \mathrm{ha}^{-1}\right)+\mathrm{OF}\left(25 \mathrm{~L} \mathrm{ha}^{-1}\right)$; T4-metribuzin $\left(1.920 \mathrm{~g} \mathrm{ha}^{-1}\right)$; T5-metribuzin $\left(1.920 \mathrm{~g} \mathrm{ha}^{-1}\right)+\mathrm{OF}\left(25 \mathrm{~L} \mathrm{ha}^{-1}\right)$; T6-metribuzin $\left(1.344 \mathrm{~g} \mathrm{ha}^{-1}\right)+\mathrm{OF}\left(25 \mathrm{~L} \mathrm{ha}^{-1}\right)$; T7-amicarbazone $\left(1.400 \mathrm{~g} \mathrm{ha}^{-1}\right)$; T8-amicarbazone $\left(1.400 \mathrm{~g} \mathrm{ha}^{-1}\right)+\mathrm{OF}\left(25 \mathrm{~L} \mathrm{ha}^{-1}\right)$; T9-amicarbazone $\left(0,980 \mathrm{~g} \mathrm{ha}^{-1}\right)+\mathrm{OF}\left(25 \mathrm{~L} \mathrm{ha}^{-1}\right)$; OF-óleo fúsel; Orig.-dados originais; Letras iguais não diferem entre si pelo teste de Tukey a 5\%; maiúsculas, compara-se entre espécies; e minúsculas, entre tratamentos.

Já a espécie Ipomoea quamoclit (Tabela 4) demonstrou ser mais tolerante quando tratada com óleo fúsel associado aos herbicidas, em comparação com os herbicidas usados isoladamente - tendência não significativa pelo teste de médias. Contudo, amicarbazone $\left(1.400 \mathrm{~g} \mathrm{ha}^{-1}\right)+$ OF $\left(25 \mathrm{~L} \mathrm{ha}^{-1}\right)$ proporcionou acréscimo no controle quando comparado ao herbicida utilizado isoladamente. No entanto, a análise estatística detectou menor controle somente para o uso de metribuzin (1.344 $\left.\mathrm{g} \mathrm{ha}^{-1}\right)$ + OF (25 L ha $\left.{ }^{-1}\right)$; este tratamento também foi menos eficaz para esta espécie quando comparado entre espécies, principalmente aos 60 DAT. Já o metribuzin isolado apresentou excelente controle sobre esta espécie, sendo o mesmo observado por Christoffoleti et al. (2006).

Brachiaria decumbens foi controlada pelos tratamentos estudados, com ausência de diferenças significativas entre eles (Tabela 4). Esta espécie também demonstrou ser suscetivel ao controle proporcionado pelos tratamentos estudados, inclusive aqueles que tiveram as doses dos herbicidas reduzidas e associadas ao óleo fúsel.
Quanto à espécie Euphorbia heterophylla, observou-se maior tolerância à maioria dos tratamentos empregados e também quando comparada entre espécies (Tabela 4). Os melhores resultados foram obtidos até os 60 DAT com o uso de diuronthexazinone isolado, amicarbazone isolado e amicarbazone (1.400 $\left.\mathrm{g} \mathrm{ha}^{-1}\right)+$ OF $\left(25 \mathrm{~L} \mathrm{ha}^{-1}\right)$, demonstrando a não viabilidade do uso do óleo fúsel associado aos herbicidas. Para Azania et al. (2008), a mistura do óleo fúsel com glyphosate apresentou-se ineficaz para o controle de Cyperus spp. e Commelina spp.; apesar de apresentarem partes amareladas e redução de tamanho, elas não foram completamente controladas.

Aos 90 DAT, devido à ausência do desdobramento estatístico, pôde-se verificar os dados referentes à densidade e massa seca das plantas daninhas aos 90 DAT (Figura 1). Na ocasião, constatou-se que especialmente em I. quamoclit e E. heterophylla os tratamentos com metribuzin (1.920 $\left.\mathrm{g} \mathrm{ha}^{-1}\right)+$ OF $\left(25 \mathrm{~L} \mathrm{ha}^{-1}\right)$ e metribuzin $\left(1.344 \mathrm{~g} \mathrm{ha}^{-1}\right)+\mathrm{OF}\left(25 \mathrm{~L} \mathrm{ha}^{-1}\right)$ proporcionaram maiores valores de densidades de plantas aos 90 DAT. Esse resultado pode ser 
indicativo de que os tratamentos também não controlaram as espécies aos 90 DAT.

A massa seca de ambas as espécies teve comportamento diferenciado quando se consideraram os mesmos tratamentos; em I. quamoclit os valores foram maiores que em E. heterophylla. Isso pode ter ocorrido devido às diferenças biológicas das espécies, pois I. quamoclit possui hábito de crescimento trepador e E. heterophylla é herbácea com crescimento ereto (Kissmann \& Groth, 1999). Essa característica biológica pode explicar os valores observados para ambas as espécies na Figura 1, especialmente nos tratamentos que proporcionaram menores controles.

As espécies $P$. maximum, $B$. decumbens e A. deflexus aos 90 DAT apresentaram-se com densidades populacionais menores que 10 plantas $\mathrm{m}^{-2}$ (Figura 1), demonstrando que o controle pelos tratamentos utilizados foi eficaz. Entretanto, a massa seca de $P$. maximum apresentou-se elevada principalmente nos tratamentos metribuzin $\left(1.344 \mathrm{~g} \mathrm{ha}^{-1}\right)+\mathrm{OF}$ (25 $\left.\mathrm{L} \mathrm{ha}^{-1}\right)$; amicarbazone (1.400 $\left.\mathrm{g} \mathrm{ha}^{-1}\right)$; e amicarbazone (980 $\left.\mathrm{g} \mathrm{ha}^{-1}\right)$ + OF (25 $\left.\mathrm{L} \mathrm{ha}^{-1}\right)$.

No período de até 60 DAT, a aplicação dos herbicidas diuronthexazinone, metribuzin e amicarbazone em dose completa foi eficaz no controle das espécies estudadas; quando em dose completa ou $70 \%$ da dose e associados com óleo fúsel, apresentaram ainda controle satisfatório sobre as espécies, exceto para I. quamoclit e E. heterophylla.

\section{Seletividade dos tratamentos}

As injúrias causadas à cultura pelos tratamentos não foram superiores a $30 \%$ na primeira quinzena após aplicação, com total recuperação no final do primeiro mês depois da aplicação dos tratamentos (Figura 2). Esses resultados demonstram que os tratamentos foram seletivos à cultura, pois os sintomas de intoxicação proporcionados foram considerados leves.

Aos 15 DAT (Figura 2), os sintomas de intoxicação foram maiores sobre a cultura quando os herbicidas foram associados ao óleo fúsel; no entanto, esses valores não diferiram estatisticamente quando comparados aos tratamentos herbicidas sem adição de óleo fúsel, exceto metribuzin (1.920 $\left.\mathrm{g} \mathrm{ha}^{-1}\right)$, que não proporcionou injúrias.
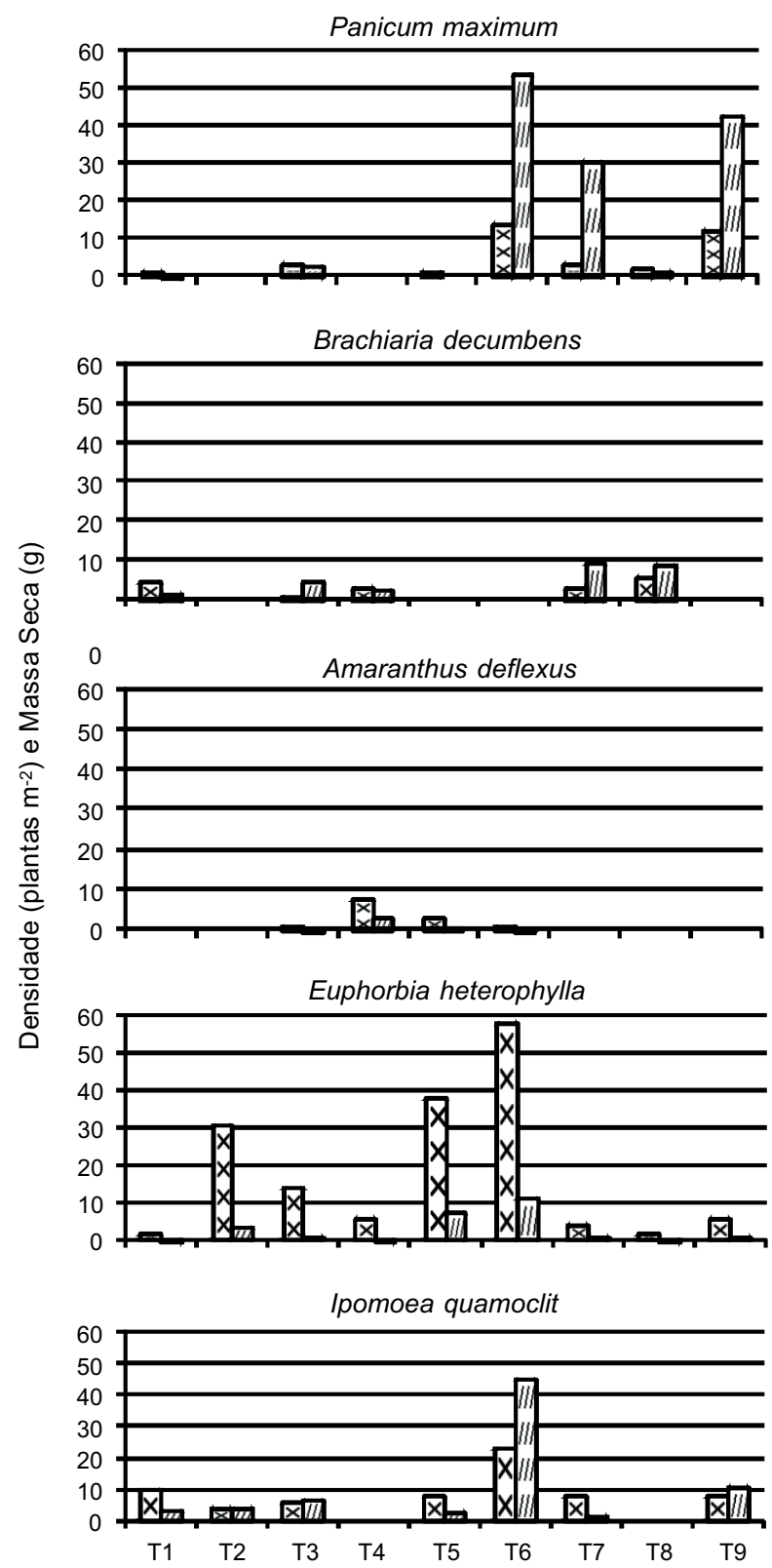

Figura 1 - Densidade e massa seca das plantas daninhas estudadas, para os diferentes tratamentos aos 90 DAT, Ribeirão Preto-SP, 2008. x - densidade (plantas $\mathrm{m}^{-2}$ ); /// massa seca (g); OF-óleo fúsel; T1-diuron+hexazinone $\left(1.170 / 0,330 \mathrm{~g} \mathrm{ha}^{-1}\right)+\mathrm{OF}\left(0 \mathrm{~L} \mathrm{ha}^{-1}\right) ;$ T2-diuron+hexazinone $\left(1.170 / 0,330 \mathrm{~g} \mathrm{ha}^{-1}\right)+\mathrm{OF}\left(25 \mathrm{~L} \mathrm{ha}^{-1}\right)$; T3 diuron/hexazinone $\left(0,819 / 0,231 \mathrm{~g} \mathrm{ha}^{-1}\right)+\mathrm{OF}\left(25 \mathrm{~L} \mathrm{ha}^{-1}\right) ; \mathrm{T} 4$ metribuzin (1.920 $\left.\mathrm{g} \mathrm{ha}^{-1}\right)+$ OF $\left(0 \mathrm{~L} \mathrm{ha}^{-1}\right)$; T5-metribuzin $\left(1.920 \mathrm{~g} \mathrm{ha}^{-1}\right)$ + OF $\left(25 \mathrm{~L} \mathrm{ha}^{-1}\right)$; T6-metribuzin $\left(1.344 \mathrm{~g} \mathrm{ha}^{-1}\right)+\mathrm{OF}$ (25 L ha-1); T7-amicarbazone (1.400 $\left.\mathrm{g} \mathrm{ha}^{-1}\right)+\mathrm{OF}\left(0 \mathrm{~L} \mathrm{ha}^{-1}\right)$; T8-amicarbazone (1.400 $\left.\mathrm{g} \mathrm{ha}^{-1}\right)+\mathrm{OF}\left(25 \mathrm{~L} \mathrm{ha}^{-1}\right)$; T9amicarbazone $\left(0,980 \mathrm{~g} \mathrm{ha}^{-1}\right)+$ OF $\left(25 \mathrm{~L} \mathrm{ha}^{-1}\right)$ aos 90 DAT. 
O modo de ação do subproduto pode ter contribuído para os maiores valores observados aos 15 DAT, uma vez que o óleo fúsel causa injúrias nas folhas da cana-de-açúcar similares às dos herbicidas dessecantes não sistêmicos, que podem levar as plantas à erradicação. Entretanto, como a quantidade adicionada à calda dos tratamentos foi pequena, não foi suficiente para proporcionar prejuízos maiores, refletindo na ausência de sintomas aos 30 DAT.

Sintomas de Intoxicação aos 15 DAT

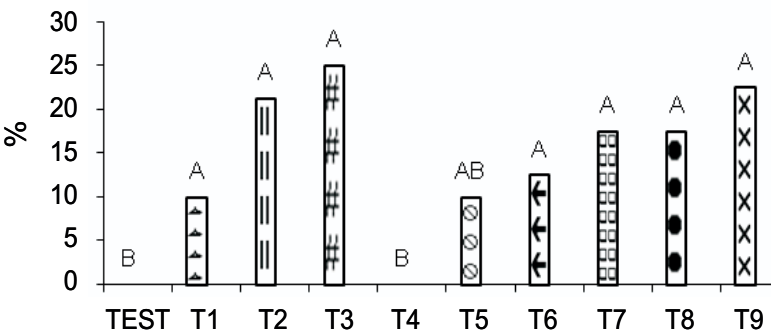

A seletividade dos herbicidas também foi constatada observando-se os valores de altura, estande da cultura aos 30, 60 e 90 DAT e o diâmetro médio dos colmos aos 90 DAT, pois não houve diferenças significativas entre os tratamentos (Tabela 5). Esses resultados indicaram a seletividade dos herbicidas isolados e também associados ao óleo fúsel quanto às variáveis avaliadas.

Os tratamentos com óleo fúsel apresentaram tendência em reduzir a altura, o estande

Sintomas de Intoxicação aos 30 DAT

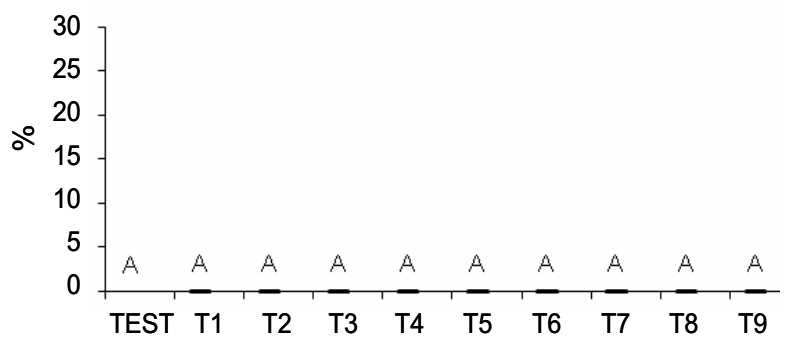

Figura 2 - Sintomas visuais de intoxicação em \% da cultura aos 15 e 30 DAT, Ribeirão Preto-SP, 2008. T1-diuron+ hexazinone $\left(1.170 / 0,330 \mathrm{~g} \mathrm{ha}^{-1}\right)$; T2-diuron+hexazinone $\left(1.170 / 0,330 \mathrm{~g} \mathrm{ha}^{-1}\right)+\mathrm{OF}\left(25 \mathrm{~L} \mathrm{ha}^{-1}\right)$; T3-diuron+hexazinone $\left(0,819 / 0,231 \mathrm{~g} \mathrm{ha}^{-1}\right)+\mathrm{OF}\left(25 \mathrm{~L} \mathrm{ha}^{-1}\right)$; T4-metribuzin $\left(1.920 \mathrm{~g} \mathrm{ha}^{-1}\right)$; T5-metribuzin $\left(1.920 \mathrm{~g} \mathrm{ha}^{-1}\right)+\mathrm{OF}\left(25 \mathrm{~L} \mathrm{ha}{ }^{-1}\right)$; T6-metribuzin $\left(1.344 \mathrm{~g} \mathrm{ha}^{-1}\right)+\mathrm{OF}\left(25 \mathrm{~L} \mathrm{ha}^{-1}\right)$; T7-amicarbazone $\left(1.400 \mathrm{~g} \mathrm{ha}^{-1}\right)$; T8-amicarbazone $\left(1.400 \mathrm{~g} \mathrm{ha}^{-1}\right)+\mathrm{OF}^{-1}$ (25 L ha-1); T9-amicarbazone $\left(0,980 \mathrm{~g} \mathrm{ha}^{-1}\right)+$ OF $\left(25 \mathrm{~L} \mathrm{ha}^{-1}\right)$; TEST- testemunha; OF-óleo fúsel; DAT - dias após tratamento.

Tabela 5 - Efeitos da aplicação de diferentes herbicidas isolados e associados ao óleo fúsel sobre estande, altura e diâmetro de colmos da cana-de-açúcar, em diferentes épocas de avaliação, Ribeirão Preto-SP, 2008

\begin{tabular}{|c|c|c|c|c|c|c|c|}
\hline \multirow{3}{*}{ Tratamento } & \multicolumn{3}{|c|}{ Estande } & \multicolumn{3}{|c|}{ Altura } & \multirow{3}{*}{$\begin{array}{c}\text { Diâmetro } \\
\text { DAT } \\
90\end{array}$} \\
\hline & \multicolumn{3}{|c|}{ DAT } & \multicolumn{3}{|c|}{ DAT } & \\
\hline & 30 & 60 & 90 & 30 & 60 & 90 & \\
\hline diuron+hexazinone $\left(1.170 / 0,330 \mathrm{~g} \mathrm{ha}^{-1}\right)$ & $24,28 \mathrm{~A}$ & $13,95 \mathrm{~A}$ & $17,00 \mathrm{~A}$ & $0,85 \mathrm{~A}$ & $1,35 \mathrm{~A}$ & $1,89 \mathrm{~A}$ & $2,90 \mathrm{~A}$ \\
\hline diuron+hexazinone $\left(1.170 / 0,330 \mathrm{~g} \mathrm{ha}^{-1}\right)+\mathrm{OF}\left(25 \mathrm{~L} \mathrm{ha}^{-1}\right)$ & $21,48 \mathrm{~A}$ & $13,18 \mathrm{~A}$ & $15,48 \mathrm{~A}$ & $0,77 \mathrm{~A}$ & $1,27 \mathrm{~A}$ & $1,79 \mathrm{~A}$ & $2,80 \mathrm{~A}$ \\
\hline diuron+hexazinone $\left(0,819 / 0,231 \mathrm{~g} \mathrm{ha}^{-1}\right)+\mathrm{OF}\left(25 \mathrm{~L} \mathrm{ha}^{-1}\right)$ & $20,90 \mathrm{~A}$ & $11,60 \mathrm{~A}$ & $14,50 \mathrm{~A}$ & $0,74 \mathrm{~A}$ & $1,31 \mathrm{~A}$ & $1,70 \mathrm{~A}$ & $2,78 \mathrm{~A}$ \\
\hline metribuzin $\left(1.920 \mathrm{~g} \mathrm{ha}^{-1}\right)$ & $27,08 \mathrm{~A}$ & $14,73 \mathrm{~A}$ & $17,56 \mathrm{~A}$ & $0,84 \mathrm{~A}$ & $1,46 \mathrm{~A}$ & $1,96 \mathrm{~A}$ & $2,88 \mathrm{~A}$ \\
\hline metribuzin $\left(1.920 \mathrm{~g} \mathrm{ha}^{-1}\right)+\mathrm{OF}\left(25 \mathrm{~L} \mathrm{ha}^{-1}\right)$ & $23,45 \mathrm{~A}$ & $13,48 \mathrm{~A}$ & $15,28 \mathrm{~A}$ & $0,77 \mathrm{~A}$ & $1,16 \mathrm{~A}$ & $1,64 \mathrm{~A}$ & $2,80 \mathrm{~A}$ \\
\hline metribuzin $\left(1.344 \mathrm{~g} \mathrm{ha}^{-1}\right)+\mathrm{OF}\left(25 \mathrm{~L} \mathrm{ha}^{-1}\right)$ & $22,28 \mathrm{~A}$ & $13,00 \mathrm{~A}$ & $16,20 \mathrm{~A}$ & $0,68 \mathrm{~A}$ & $1,31 \mathrm{~A}$ & $1,80 \mathrm{~A}$ & $2,73 \mathrm{~A}$ \\
\hline amicarbazone $\left(1.400 \mathrm{~g} \mathrm{ha}^{-1}\right)$ & $21,35 \mathrm{~A}$ & $12,30 \mathrm{~A}$ & $14,88 \mathrm{~A}$ & $0,77 \mathrm{~A}$ & $1,33 \mathrm{~A}$ & $1,73 \mathrm{~A}$ & $2,75 \mathrm{~A}$ \\
\hline amicarbazone $\left(1.400 \mathrm{~g} \mathrm{ha}^{-1}\right)+\mathrm{OF}\left(25 \mathrm{~L} \mathrm{ha}^{-1}\right)$ & $19,43 \mathrm{~A}$ & $12,30 \mathrm{~A}$ & $14,53 \mathrm{~A}$ & $0,76 \mathrm{~A}$ & $1,29 \mathrm{~A}$ & $1,63 \mathrm{~A}$ & $2,93 \mathrm{~A}$ \\
\hline amicarbazone $\left(0,980 \mathrm{~g} \mathrm{ha}^{-1}\right)+$ OF $\left(25 \mathrm{~L} \mathrm{ha}^{-1}\right)$ & $20,73 \mathrm{~A}$ & $11,60 \mathrm{~A}$ & $14,08 \mathrm{~A}$ & $0,75 \mathrm{~A}$ & $1,30 \mathrm{~A}$ & $1,69 \mathrm{~A}$ & $2,85 \mathrm{~A}$ \\
\hline \multirow[t]{2}{*}{ Testemunha } & $24,08 \mathrm{~A}$ & $14,10 \mathrm{~A}$ & $17,28 \mathrm{~A}$ & $0,91 \mathrm{~A}$ & $1,44 \mathrm{~A}$ & $1,87 \mathrm{~A}$ & $2,83 \mathrm{~A}$ \\
\hline & \multicolumn{7}{|c|}{$\mathrm{F}$} \\
\hline Blocos & $4,35^{*}$ & $0,3 \mathrm{NS}$ & $0,47 \mathrm{NS}$ & $3,9^{*}$ & $1,77 \mathrm{NS}$ & $0,57 \mathrm{NS}$ & $1,92 \mathrm{NS}$ \\
\hline Tratamentos & $1,53 \mathrm{NS}$ & $1,11 \mathrm{NS}$ & $0,90 \mathrm{NS}$ & $1,76 \mathrm{NS}$ & $1,44 \mathrm{NS}$ & $2,25 \mathrm{NS}$ & $0,79 \mathrm{NS}$ \\
\hline CV $(\%)$ & 16,09 & 15,54 & 16,96 & 12,51 & 10,76 & 8,44 & 5,17 \\
\hline
\end{tabular}

Estande em número de colmos por metro linear; altura em metros; e diâmetro em centímetros; DAT - dias após tratamento. OF - óleo fúsel. * significativo a 5\% de probabilidade pelo teste F. NS - não significativo. Letras iguais na mesma coluna não diferem entre si pelo teste de Tukey a $5 \%$ 
e o diâmetro da cultura, quando comparados ao respectivo tratamento com ausência do subproduto ou com a testemunha em todas as épocas avaliadas (Tabela 5). As maiores injúrias proporcionadas pelo óleo fúsel aos 15 DAT (Figura 2) podem ter contribuído com esses resultados, em função da menor capacidade fotossintética devido a cloroses e necroses presentes nas folhas e ao maior gasto energético para recuperação, a qual foi observada já aos 30 DAT.

A seletividade dos tratamentos também foi observada ao analisar as características tecnológicas da cana-de-açúcar (Tabela 6), que não apresentaram diferenças entre os tratamentos nas variáveis analisadas, excetuando-se os valores do Brix. Entretanto, os valores observados para as características tecnológicas são divergentes daqueles proporcionados pela cana-de-açúcar quando está fisiologicamente madura. Esse resultado foi obtido antes das induções climáticas à maturação da cultura e, segundo Casagrande (1991), se deve à deficiência hídrica e térmica e a características do período de outono e inverno para condições paulistas.

Verificando os dados das análises tecnológicas (Tabela 6), estes demonstraram diferenças significativas apenas para os valores de Brix; diuronthexazinone $\left(1.170+330 \mathrm{~g} \mathrm{ha}^{-1}\right)$ + OF $\left(25 \mathrm{~L} \mathrm{ha}^{-1}\right)$ e metribuzin (1.920 $\left.\mathrm{g} \mathrm{ha}^{-1}\right)$ foram os tratamentos que apresentaram menores valores para esta variável. Entretanto, a maioria dos tratamentos apresentou valores similares aos da testemunha, indicando que existe uma tendência de a concentração de sólidos solúveis se estabilizar próximo à das testemunha para todos os tratamentos.

Ocorre que os valores convencionais de sólidos solúveis devem estar entre $18 \mathrm{e}$ $20{ }^{\circ}$ Brix na maturidade da cana-de-açúcar (Casagrande, 1991). Contudo, a cana-de-açúcar avaliada aos 90 DAT (210 dias após a última colheita) ainda precisa de mais alguns meses para atingir essa quantidade de Brix. As demais características tecnológicas avaliadas não mostraram diferenças estatísticas, podendo ser isso indicativo de seletividade dos tratamentos já aos 90 DAT (210 dias após colheita), mesmo sem a cultura ter atingido o ápice da maturação.

Em relação à estimativa de produção, observou-se (Tabela 6) que o tratamento amicarbazone $\left(1.400 \mathrm{~g} \mathrm{ha}^{-1}\right)+$ OF $\left(25 \mathrm{~L} \mathrm{ha}^{-1}\right)$ diferiu da testemunha e os demais tratamentos foram similares entre si, havendo a tendência de redução da produtividade quando o óleo fúsel foi associado aos herbicidas, assim

Tabela 6 - Efeitos da aplicação de diferentes herbicidas isolados e associados ao óleo fúsel sobre a produção e análise tecológica da cana-de-açúcar aos 90 dias após aplicação. Ribeirão Preto-SP, 2008

\begin{tabular}{|c|c|c|c|c|c|c|c|}
\hline \multirow{2}{*}{ Tratamento } & \multirow{2}{*}{$\begin{array}{l}\text { Produção } \\
\left(\mathrm{t} \mathrm{ha}^{-1}\right)\end{array}$} & \multicolumn{4}{|c|}{$\%$ Caldo } & \multirow{2}{*}{$\begin{array}{c}\% \text { Cana } \\
\text { Fibra }\end{array}$} & \multirow{2}{*}{$\operatorname{ATR}^{1 /}$} \\
\hline & & BRIX & POL & Pureza & $\mathrm{AR}$ & & \\
\hline diuron+hexazinone $\left(1.170 / 0,330 \mathrm{~g} \mathrm{ha}^{-1}\right)$ & $114,26 \mathrm{AB}$ & $11,15 \mathrm{~A}$ & $6,72 \mathrm{~A}$ & $60,09 \mathrm{~A}$ & $1,42 \mathrm{~A}$ & $8,58 \mathrm{~A}$ & $68,59 \mathrm{~A}$ \\
\hline diuron+hexazinone $\left(1.170 / 0,330 \mathrm{~g} \mathrm{ha}^{-1}\right)+\mathrm{OF}\left(25 \mathrm{~L} \mathrm{ha}^{-1}\right)$ & $100,37 \mathrm{AB}$ & $9,10 \mathrm{C}$ & $4,53 \mathrm{~A}$ & $49,57 \mathrm{~A}$ & $1,76 \mathrm{~A}$ & $8,25 \mathrm{~A}$ & $53,08 \mathrm{~A}$ \\
\hline diuron+hexazinone $\left(0,819 / 0,231 \mathrm{~g} \mathrm{ha}^{-1}\right)+\mathrm{OF}\left(25 \mathrm{~L} \mathrm{ha}^{-1}\right)$ & $83,35 \mathrm{AB}$ & $9,91 \mathrm{ABC}$ & $5,68 \mathrm{~A}$ & $57,11 \mathrm{~A}$ & $1,52 \mathrm{~A}$ & $8,53 \mathrm{~A}$ & $60,45 \mathrm{~A}$ \\
\hline metribuzin $\left(1.920 \mathrm{~g} \mathrm{ha}^{-1}\right)$ & $112,96 \mathrm{AB}$ & $9,41 \mathrm{BC}$ & $5,04 \mathrm{~A}$ & $53,17 \mathrm{~A}$ & $1,64 \mathrm{~A}$ & $8,07 \mathrm{~A}$ & $56,87 \mathrm{~A}$ \\
\hline metribuzin $\left(1.920 \mathrm{~g} \mathrm{ha}^{-1}\right)+\mathrm{OF}\left(25 \mathrm{~L} \mathrm{ha}^{-1}\right)$ & $91,51 \mathrm{AB}$ & $10,60 \mathrm{ABC}$ & $6,18 \mathrm{~A}$ & $57,52 \mathrm{~A}$ & $1,52 \mathrm{~A}$ & $8,34 \mathrm{~A}$ & $64,42 \mathrm{~A}$ \\
\hline metribuzin $\left(1.344 \mathrm{~g} \mathrm{ha}^{-1}\right)+\mathrm{OF}\left(25 \mathrm{~L} \mathrm{ha}^{-1}\right)$ & $99,88 \mathrm{AB}$ & $10,61 \mathrm{ABC}$ & $6,50 \mathrm{~A}$ & $61,27 \mathrm{~A}$ & $1,40 \mathrm{~A}$ & $8,06 \mathrm{~A}$ & $66,70 \mathrm{~A}$ \\
\hline amicarbazone $\left(1.400 \mathrm{~g} \mathrm{ha}^{-1}\right)$ & $91,32 \mathrm{AB}$ & $10,44 \mathrm{ABC}$ & $6,07 \mathrm{~A}$ & $57,85 \mathrm{~A}$ & $1,49 \mathrm{~A}$ & $8,53 \mathrm{~A}$ & $63,94 \mathrm{~A}$ \\
\hline amicarbazone $\left(1.400 \mathrm{~g} \mathrm{ha}^{-1}\right)+\mathrm{OF}\left(25 \mathrm{~L} \mathrm{ha}^{-1}\right)$ & $80,78 \mathrm{~B}$ & $10,30 \mathrm{ABC}$ & $5,91 \mathrm{~A}$ & $56,88 \mathrm{~A}$ & $1,53 \mathrm{~A}$ & $8,30 \mathrm{~A}$ & $62,84 \mathrm{~A}$ \\
\hline amicarbazone $\left(0,980 \mathrm{~g} \mathrm{ha}^{-1}\right)+\mathrm{OF}\left(25 \mathrm{~L} \mathrm{ha}^{-1}\right)$ & $82,42 \mathrm{AB}$ & $10,01 \mathrm{ABC}$ & $5,56 \mathrm{~A}$ & $54,74 \mathrm{~A}$ & $1,59 \mathrm{~A}$ & $8,45 \mathrm{~A}$ & $60,20 \mathrm{~A}$ \\
\hline \multirow[t]{2}{*}{ Testemunha } & $124,02 \mathrm{~A}$ & $10,94 \mathrm{AB}$ & $6,68 \mathrm{~A}$ & $60,77 \mathrm{~A}$ & $1,41 \mathrm{~A}$ & $8,35 \mathrm{~A}$ & $67,81 \mathrm{~A}$ \\
\hline & \multicolumn{7}{|c|}{$\mathrm{F}$} \\
\hline Blocos & $3,10^{*}$ & $7,61 * *$ & $3,33^{*}$ & $1,26 \mathrm{NS}$ & $7,47 * *$ & $1189,27 * *$ & $4,69^{* *}$ \\
\hline Tratamentos & $2,62^{*}$ & $3,28 * *$ & $2,05 \mathrm{NS}$ & $1,44 \mathrm{NS}$ & $1,51 \mathrm{NS}$ & $0,77 \mathrm{NS}$ & $2,18 \mathrm{NS}$ \\
\hline $\mathrm{CV}(\%)$ & 9,58 & 6,94 & 16,86 & 10,59 & 12,17 & 4,98 & 10,69 \\
\hline
\end{tabular}

OF - óleo fúsel. ${ }^{1 /}$ Açúcar total recuperável em kg de açúcar por tonelada de colmos. ** significativo a $1 \%$ de probabilidade pelo teste $\mathrm{F}$. * significativo a $5 \%$ de probabilidade pelo teste F. NS - não significativo. Letras iguais na mesma coluna não diferem entre si pelo teste de Tukey a $5 \%$. 
como aconteceu com as variáveis altura, estande e diâmetro de colmos.

No período de até 90 DAT (210 dias da última colheita), os herbicidas diuron+ hexazinone, metribuzin e amicarbazone em dose completa foram seletivos ao cultivar IACSP 93-3046, ao comparar com a testemunha as variáveis altura, estande, diâmetro e produção de colmos, assim também como aos atributos qualitativos. Entretanto, apenas diuronthexazinone e amicarbazone em dose completa associados com óleo fúsel não foram seletivos à concentração de sólidos solúveis no caldo e na produção de colmos, respectivamente.

\section{AGRADECIMENTOS}

Ao CNPq/IAC, pela bolsa de Iniciação Científica, e ao PqC. Dr. Marcos Landell, pelo apoio em infraestrutura.

\section{LITERATURA CITADA}

AGRIANUAL, 2008: anuário da agricultura brasileira. São Paulo: Instituto FNP, 2008. p. 227-244.

AZANIA, A. A. P. M. et al. Emergência e desenvolvimento de guanxuma (Sida rhombifolia), capim-braquiária (Brachiaria decumbens) e cana-de-açúcar (Saccharum spp.) influenciados por subprodutos da destilação do álcool. Planta Daninha, v. 22, n. 3 , p. $331-336,2004$

AZANIA, A. A. P. M. et al. Germinação de sementes de Sida rhombifolia e Brachiaria decumbens influenciada por vinhaça, flegmaça e óleo fúsel. Planta Daninha, v. 21, n. 3, p. $443-449,2003$.

AZANIA, A. A. P. M. et al. Aplicação de óleo fúsel isolado e em mistura com glifosato na pós-emergência tardia de plantas daninhas. Planta Daninha, v. 26, n. 1, p. 231-236, 2008.

AZANIA, C. A. M.; AZANIA, A. A. P. M.; FURTADO, D. E. Biologia e manejo de plantas daninhas em cana-de-açúcar. In: SEGATO, S. V. et al. Atualização em produção de canade-açúcar. Piracicaba: 2006. p. 173-191.

BRASIL. Ministério da Agricultura, Pecuária e Abastecimento. Brasília: 2007. Disponível em: <http:// extranet.agricultura.gov.br/agrofit_cons/ principal_agrofit_cons>. Acesso em:14 abr. 2008.
CASAGRANDE, A. A. Tópicos de morfologia e fisiologia da cana-de-açúcar. Jaboticabal: FUNEP, 1991. 157 p.

CHRISTOFFOLETI, P. J. et al. Carfentrazone-ethyl aplicado em pós-emergência para o controle de Ipomoea spp. e Commelina benghalensis na cultura da cana-de-açúcar. Planta Daninha, v. 24, n. 1, p. 83-90, 2006

CENTRO INTEGRADO DE INFORMAÇÕES METEOROLÓGICAS - CIIAGRO. Disponível em: <http:// www.ciiagro.sp.gov.br>. Acesso em: 5 jul. 2008.

CLEMENT, A. A.; LAMMEL, J. S.; BARBOSA, J. C Controle de plantas daninhas em cana-de-açúcar (Saccharum officinarum) com hexazinone e suas misturas com diuron, em pré-emergência. Planta Daninha, v. 2, n. 1, p. 85-88, 1979.

CONSELHO DOS PRODUTORES DE CANA-DEAÇÚCAR, AÇÚCAR E ÁLCOOL DO ESTADO DE SÃO PAULO - CONSECANA. Manual de Instruções. 5.ed. Piracicaba: 2006. 112 p. Disponível em: <http:// www.orplana.com.br/manual_2006.pdf $>$. Acesso em: 4 jul. 2008.

KISSMANN, G. K.; GROTH, D. Plantas infestantes e nocivas. 2.ed. São Paulo: Basf, 1997. Tomo I.

KISSMANN, G. K.; GROTH, D. Plantas infestantes e nocivas. 2.ed. São Paulo: Basf, 1999. Tomo II

LANDELL, M. G. A. Método experimental: Ensaios de competição em cana-de-açúcar. In: MARTINS, A. L. M.; LANDELL, M. G. A. Conceitos e critérios para avaliação experimental em cana-de-açúcar utilizados no Programa Cana IAC. Pindorama: Instituto Agronômico, 1995. p. 2-14.

LIMA, U. A. Estudos dos principais fatores que afetam os componentes do coeficiente não-álcool das aguardentes de cana. 1964. $141 \mathrm{f}$. Tese (Cátedra em Tecnologia do Açúcar e do Álcool) - Escola Superior de Agricultura "Luiz de Queiroz", Piracicaba, 1964

MACIEL, C. D. G. et al., Eficiência e seletividade dos herbicidas trifloxysulfuron-sodium + ametryne e hexazinone + diuron em função da tecnologia de aplicação e do manejo mecânico da palha de cana-de-açúcar na linha de plantio. Planta Daninha, v. 26, n. 3, p. 665-676, 2008.

PÉREZ, E. R.; CARDOSO, D. R.; FRANCO, D. W. Análise dos álcoois, ésteres e compostos carbonílicos em amostras de óleo fúsel. Química Nova, v. 24, n. 1, p. 10-12, 2001.

RODRIGUES, B. N.; ALMEIDA, F. S. Guia de herbicidas. 5.ed. Londrina: 2005. 592 p. 